
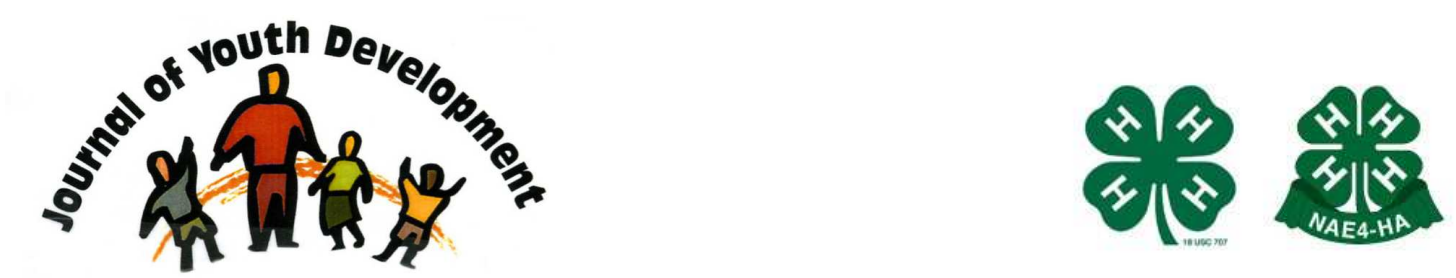

Bridging Research \& Practice

\title{
The Youth Relatedness Scale: Development of a New Evaluation Tool for Youth Programs
}

\author{
Melissa H. D'Eloia \\ Department of Recreation and Leisure Studies \\ California State University - Long Beach \\ Long Beach, CA \\ mhough@csulb.edu \\ Jim Sibthorp \\ Department of Parks, Recreation, and Tourism \\ University of Utah
}




\title{
JOURNAL OF YOUTH DEVELOPMENT \\ bridging research and practice

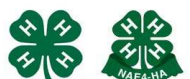

\section{The Youth Relatedness Scale: Development of a New Evaluation Tool for Youth Programs}

\author{
Melissa H. D’Eloia \\ California State University-Long Beach \\ Jim Sibthorp \\ University of Utah
}

\begin{abstract}
This paper examines a study to develop a reliable measure of relatedness that utilizes language appropriate for youth, is simple for staff to administer in a field-based setting, and is consistent with the Youth Outcomes Battery. Pilot instruments were distributed to three residential summer camps serving female and male campers between the ages 10-17. The results of this study indicate that the Youth Relatedness Scale is an easy-to-use measure that exhibits good evidence of internal consistency and shows good criterion evidence of validity for this population of youth. This study was a positive step towards providing a theoretically grounded, simple, and versatile measure that captures youth perceptions of relatedness and that youth program administrators can employ to evaluate their programs.
\end{abstract}

\section{Introduction}

Today, more than ever, professionals working in youth settings are expected to document the value and purpose of their programs. The documentation of such outcomes provides evidence of program efficacy, allows providers to meet industry standards, satisfies parental expectations, and plays a role in funding applications to support youth programs (American Camp Association, 2005). Despite a widespread movement toward youth program quality, which advocates a focus on programmatic factors instead of outcomes, many funding agencies and external stakeholders still require summative outcome evaluations. The complexities inherent within youth programs, combined with the multifaceted nature of numerous desired outcomes, makes documenting these developmental gains a challenge for professionals and scholars alike. 
One such effort to assist youth professionals in outcomes documentation and program evaluation processes is the Youth Outcomes Battery (YOB; American Camp Association, 2011). The YOB, developed in partnership with the American Camp Association (ACA), measures eleven youth development outcomes that are common to many youth programs such as independence, teamwork, friendship skills, and perceived competence. Furthermore, the researchers (Ellis \& Sibthorp, 2006) designed this tool with the specific needs of practitioners in mind such that all of the measures are short in length, easy to administer, age appropriate, and psychometrically sound. Despite the utility and success of this tool, there are many outcomes (e.g., identity formation, youth engagement, and relatedness) common to youth programs that the YOB does not yet assess.

Sense of relatedness is an outcome of interest for many youth development programs. The youth development literature identifies sense of relatedness as a critical mechanism that may lead to a myriad of positive social, emotional, and cognitive outcomes (Anderman, 1999; Catalano, Haggerty, Oesterle, Fleming, \& Hawkins, 2004; Deci \& Ryan, 2000; Wentzel \& Caldwell, 1997). Relatedness is also a vital component in fostering and supporting a young person's growth and identity formation (MacDonald \& Valdivieso, 2000). Youth may gain more from their participation when programs build connections and bonds between staff, youth, and the organization at large (Anderson-Butcher, 2000). Based on the above research, programs that want to realize greater developmental gains should incorporate an environment that encourages a sense of relatedness among program staff and participants. Summer camps are one context that seems particularly conducive to fostering a sense of relatedness among youth. However, the extent to which summer camp increases camper perceptions of relatedness has largely remained undocumented.

Some past evaluation efforts (e.g., Roark, 2008; Thurber, Scanlin, Scheuler, \& Henderson, 2006) within the camp context have primarily concentrated on outcomes similar to relatedness, including social skill development and friendship. While these constructs contribute to the experience of relatedness, both fail to capture the affective and interpersonal nature of this construct. Camp professionals and scholars need to be able to document multifaceted developmental outcomes like relatedness in order for the camp industry to continue to thrive and reposition itself as a viable and essential youth service. Thus, the creation of a measurement tool focused on assessing a sense of relatedness is important and valuable to youth program providers and researchers. Therefore, the purpose of this study was to develop a reliable measure of relatedness that utilizes language appropriate for youth, is simple for staff to administer in a youth program setting, and is consistent with the Youth Outcomes Battery.

\section{Relatedness and Youth Programs}

With increased recognition of the potential benefits associated with relatedness, research (e.g., Anderson-Butcher \& Conroy, 2002; Gest, Welsh \& Domitrovich, 2005; Osterman, 2000; Rhodes, 2004; Whitlock, 2006) investigating how youth-serving organizations (schools and after-school programs) can foster relatedness among its staff and participants has surged. One prevailing theme ensuing from this research is that program-level characteristics and program type are significant influences on relatedness. For example, literature comparing school environments to after-school programs indicates that youth perceive out-of-school time as more conducive to developing positive peer and adult relationships than in-school time (Furrer \& Skinner, 2003). 
Schools often employ organizational practices and policies that impede student relatedness (Osterman, 2000) causing some students and researchers to describe them as "alienating institutions" (Anderman \& Maehr, 1994).

After-school programs, on the other hand, tend to be more interpersonal in nature. These programs generally encourage youth to engage in social activities that help build close bonds with their peers and program staff (Grossman \& Bulle, 2006). Research within the after-school setting points to process-level variables like program activities and staff practices as critical ingredients to fostering interpersonal relationships and a sense of relatedness (Rhodes, 2004). Youth programs that occur during out-of-school time seem to be proficient at providing youth meaningful opportunities to build positive peer and adult relationships, thereby amplifying a sense of relatedness.

Summer camp is gaining recognition as a positive force in youth development (e.g., Henderson et al., 2002; Thurber, Scanlin, Scheuler, \& Henderson, 2006). Camp provides a prominent outof-school context that may be particularly adept at enhancing a sense of relatedness among youth. Children at camp engage in a shared living experience that takes place in a novel environment, usually occurring in an outdoor setting, apart from family and friends, where they face a variety of new activities and challenges (Fullerton, Brandon, \& Arick, 2000). These experiences provide youth with a rich context to form meaningful relationships with their peers and to develop a sense of belonging. As such, the idea that summer camp can foster a sense of relatedness may be a reasonable assertion. However, most evidence supporting this notion is often either limited or anecdotal.

\section{Relatedness: Theoretical Background}

With roots in drive and motivation theories, the concept of relatedness helps explain the relationships between the environmental context, individual perceptions of belonging, and the way people think, feel, and act from a psychological perspective. Cognitively, relatedness affects people's perceptions of others, such that people will think more favorably and thoroughly about friends and relationship partners than they will about acquaintances and strangers (Osterman, 2000). People tend to classify and store information about others differently depending on whether or not they are part of one's social network or community (Ostrom, Carpenter, Sedikides, \& Li, 1993).

Research suggests that human emotions are directly connected with peoples' perceptions of relatedness. For example, a positive sense of relatedness encompasses perceptions of warmth, closeness, caring, and support (Eccles \& Gootman, 2002), which may lead to a variety of positive emotions, including happiness and joy (Fajans, 2006). Conversely, negative perceptions of relatedness, which involve perceptions of rejection, exclusion, and feeling ignored, will often engender negative emotions such as depression and unhappiness (Myers, 1992). Relatedness is also closely associated with human behavior, such that people who feel a strong sense of belonging are more likely to engage in intrinsically motivated actions (Deci \& Ryan, 2000) and experience a variety of physical and psychological benefits (Baumeister \& Leary, 1995). Research in this area largely concentrates on the study of human motivation and investigates the role relatedness plays as a primary motivator to achieve various cognitive, emotional, social, and developmental outcomes. 
One of the most contemporary and popular motivation theories aligned with this perspective is self-determination theory (Deci \& Ryan, 1985). Scholars have utilized self-determination theory to explain the relationships between needs satisfaction, motivation, and human behavior. Selfdetermination theory purports that people are naturally inclined to engage in environments and activities that support their psychological needs for autonomy, competence, and relatedness (Ryan \& Deci, 2000). Failure to foster any one of these needs is associated with deficits in intrinsic forms of motivation and psychological functioning (Deci \& Ryan, 2000). This theory defines relatedness, one of the proposed psychological needs, as individual perceptions of feeling connected to, caring for and being cared for by others, and feeling a sense of belonging (Ryan \& Deci, 2004).

Further clarifying this concept, Baumeister and Leary (1995) define relatedness as "a pervasive drive to form and maintain a minimum quantity of lasting, positive, and significant interpersonal relationships" (p. 497). They forward the argument that the human drive for relatedness is quite profound. According to these authors, people tend to form social bonds rather easily, and that they will continue to foster these relationships even under challenging circumstances. Negative and fearful circumstances, while not ideal, can produce strong interpersonal connections among people. One prominent example of this for youth is gang membership. Gangs often expose youth to or even asked them to commit violent crimes that can lead to injury, jail, or death. Nevertheless, research suggests that gangs provide youth with a powerful sense of belonging that schools and family unfortunately often fail to offer (Omizo, Omizo, \& Honda, 1997). In addition to clarifying the human need for relatedness as a driving force, Baumeister and Leary's definition highlights the complex nature of relatedness and clearly delineates three key ingredients that must be present in order for people to perceive that they belong.

First, people must perceive their interpersonal relationships as affectively pleasant and frequent. Perceptions of relatedness may occur affectively when people characterize their relationships as incorporating feelings of acceptance, caring, and value (Osterman, 2000). When youth feel cared for and valued by others, they are more likely to engage in pro-social behaviors (Solomon, Battistich, Watson, Schaps, \& Lewis, 2000), feel less distress (Wentzel, 1998), and engage in fewer disruptive behaviors (Vigil, 2004). However, positive affect alone is not sufficient. Interactions with others to whom they feel a positive connection must also be sufficiently frequent. Research has revealed that people feel a greater sense of loneliness when they experience an insufficient amount of social contact with significant others (Shaver \& Buhrmester, 1983; Simone \& Roberts, 2008). For example, these results can occur for youth in circumstances that involve divorce, long-distance relationships, or being an only child of overworked parents (Samuelsson, 1997). In each of these instances, youth have affectively pleasant and meaningful connections to others, but they do not experience adequate frequent interaction. Both, frequency and pleasant affect must be present in order for people to experience relatedness.

Second, people must also believe that their relationships are stable and long-term. In general, people prefer a few close and stable relationships to a high number of transient and superficial relationships (Caldwell \& Peplau, 1982). When people have a few close interpersonal relationships, they can experience a greater depth of emotion and understanding then when people have several fleeting interactions. Stable and long-term relationships are more likely to nurture feelings of acceptance, caring, and value, all of which are essential to fostering 
individual perceptions of relatedness (Osterman, 2000). In the context of relatedness, people favor quality over quantity, as the need for relatedness is subject to satiation and diminishing returns (Baumeister \& Leary, 1995).

Third, people desire their relationships be mutual and reciprocal in nature where all group members feel accepted, cared for, and valued (Baumeister \& Leary, 1995). The social capital literature suggests that when interpersonal relationships involve mutual and reciprocal concern, those relationships produce a social connection qualitatively different from one based on selfinterest (Schaefer-McDaniel, 2004). Friendships that are reciprocal in nature tend to have a set of mutually agreed upon norms and expectations that are likely to produce a relationship that is more emotionally supportive and lasting (Vaquera \& Kao, 2008). Reciprocity is also a key element within the theory of human relatedness (Hagerty, Lynch-Sauer, Patusky, \& Bouswema, 1993), which suggests that people prefer their relationships to include an authentic and equitable exchange of giving and taking. Therefore, based on the above literature, relatedness was defined for purposes of this study as campers' perceptions of durable, mutual, and positive interpersonal relationships.

\section{Measurement of Relatedness}

Several instruments exist within the education and psychology literature that attempt to measure relatedness. Some of these scales include Anderson-Butcher and Conroy's Sense of Belonging Scale (2002), Goodenow's Psychological Sense of School Membership Scale (1993), Hagerty \& Patusky's Sense of Belonging Inventory (1995), and Ilardi, Leone, Kasser, and Ryan's Basic Psychological Needs Scale (1993). These measures, while potentially valuable, were not appropriate for outcome evaluation with youth in field-based settings because they are too specific and contextual in nature. The Sense of Belonging Scale (Anderson-Butcher \& Conroy, 2002), for instance, measures participant perceptions of relatedness to a specific youth development program. From this scale, researchers can make inferences regarding the extent to which a youth development agency fosters participant perceptions of belonging to that specific program. The Psychological Sense of School Membership Scale (Goodenow, 1993) and the Sense of Belonging Inventory (Hagerty \& Patusky, 1995) are also too context specific as they measure whether certain social partners within a program or health care facility (e.g., peers, teachers, and nurses) promotes individual perceptions of relatedness. While these measures provide researchers a clearer understanding of belonging at the nexus of the organization, these scales fail to capture more global conceptualizations of relatedness.

In addition to these measures being too context specific, they were also constructed using theoretical frameworks that were inconsistent with Baumeister and Leary's (1995) conceptualization of relatedness. According to these authors, central to the definition of relatedness are the concepts of positivity, caring, mutuality, and duration. The above scales did not capture these concepts in conjunction. For example, the Basic Psychological Needs Scale (Ilardi et al., 1993) measures the extent to which people perceive their relationships to be caring, mutual and positive, but neglects the concept of durability. Consequently, the development of a scale that is appropriate for use within an applied, field-based setting, and measures a sense of relatedness as conceptualized by Baumeister and Leary, is essential for youth programs to demonstrate effectiveness in achieving this outcome. 


\section{Methods}

The purpose of the present study was to develop a reliable measure of relatedness that utilizes language appropriate for youth, is simple for staff to administer in a field-based camp setting, and is consistent with the Youth Outcomes Battery (American Camp Association, 2011; Ellis \& Sibthorp, 2006). Since 2006, the Youth Outcomes Battery (YOB) has gained national and international recognition within the camp industry as offering a series of easy-to-use measures that provide camp program a reliable and valid way to document participant growth. In order for this scale to be compatible with the YOB, it had to employ the same response formats and adhere to the scale length requirements. The YOB utilizes two different response formats: a current status format (typically used for a traditional pretest/posttest evaluation procedure) and a current status plus retrospective change format (typically used for a post only evaluation procedure). Each measure within the YOB has 6 to 14 questions. The shortness of each scale allows staff to customize and administer multiple measures in conjunction to effectively assess and evaluate a variety of outcomes that are relevant to the specific nature of the program while at the same time avoiding issues (e.g., too time consuming and complex) that negate staff from engaging in program evaluation procedures.

To complete this project, the researchers followed the standard practices and procedures for developing scales based on classical test theory (DeVellis, 2003). The associated literature was reviewed to define relatedness, establish domains, and generate an initial pool. Selfdetermination theory and the work of Baumeister and Leary (1995) served as the framework through which relatedness was operationalized. For purposes of this study, relatedness was defined as youths' perceptions of durable, mutual, and positive interpersonal relationships. To capture the dual nature of relatedness, mutuality was split into two content domains and labeled "cared for by others" and "caring for others." Thus, the three content domains of relatedness became (a) cared for by others, (b) caring for others, and (c) durability.

Using these three content domains, an initial item pool of approximately 30 items (10 items per domain) was generated. Through an iterative process, items were critiqued and modified based on readability and age appropriateness for the target population. Items were deleted if they incorporated words that were too complex for youth. Other items were removed because the content was either too ambiguous or redundant which reduced an initial pool of 30 items to 15 items ( 5 items per domain). This shortened item pool was sent to three experts in selfdetermination theory and relatedness in youth programs for further review. The panel of reviewers was sent a brief description of the scale that included the operational definitions of relatedness and the three content domains along with the individual scale items. The reviewers were asked to evaluate each item for content relevance, content representativeness, clarity, and appropriateness for the target population. Based on the feedback from the reviewers, the researchers identified the items the panel believed to most discretely capture the construct definition and domains. As a result, three more items were removed reducing the item pool to twelve. The ultimate goal was to produce a six-item scale with two items from each of the three content domains: cared for by others, caring for others, and durability.

The response formats for the scale were chosen to be compatible with the existing YOB. The "current status plus retrospective change" format of the instrument was used to conduct scale development and validity procedures. The benefit to using this format is that the scale measures both perceived current status and perceived change variables (Lam \& Bengo, 2003). 
The perceived current status version utilized a 6-point scale anchored at False and True. Sample items are: "I value my friends" and "I feel accepted by my peers." The retrospective change version used a 6-point scale anchored at "A lot less" and "A lot more." These items immediately follow each status item stem and ask, "is the above statement more or less true today than before [insert program name]?"

Pilot instruments were created and distributed to three ACA accredited residential summer camps serving female and male campers between the ages 10-17. Psychometric analyses were conducted and refined instruments were created based on the results. These analyses included examination of the internal structure (reliability, item-to-total correlations, inter-item correlations) of the individual instruments as well as cross-structure analysis (correlations between scale scores, validity variables, and age).

To assess the validity of the Youth Relatedness Scale, the relatedness subscale of the Basic Psychological Needs Scale by La Guardia, Ryan, Couchman, and Deci (2000) was used as a criterion validity check. Despite the shortcoming of this scale previously discussed, this scale was chosen as the most theoretically consistent. Both scales operationalize relatedness in a manner that is consistent with self-determination theory. Thus, these two measures should be empirically related, as both of these scales aim to measure similar conceptualizations of relatedness.

\section{Results}

A total of 200 pilot instruments were sent to three ACA accredited residential summer camps and 175 were returned. Data were screened and cleaned following the procedures outlined in Tabachnick and Fidell (2001). Because data were missing from several of the questionnaires, the usable sample was 155 campers (82 females and 73 males) with the mean age of 12.2 years $(S D=1.1)$. The youngest campers in the data set were 10 years old $(n=2)$, and oldest was $16(n=1)$.

In order to determine which items performed the best in measuring camper relatedness, both item and scale level statistics were examined including item-to-total correlations, descriptive statistics, item variances, and alpha-if-item removed statistics. Descriptive statistics are provided below in Table 1 for both the status and change responses; the current status plus retrospective change format provides two separate measures (perceived current status and perceived change) for each outcome. As can be seen in Table 1, many of the status items show some considerable departure from normality while the change variables approximated a normal distribution. Of the three content domains, the "caring for others" domain seemed to be the most problematic evidenced by the large ceiling effects. Thus, consideration to the item's individual performance and distribution was also considered in the final item reduction. 
Table 1

Descriptive Statistics for Initial Item Pool

\begin{tabular}{|c|c|c|c|c|c|c|}
\hline & \multicolumn{3}{|c|}{ Status Item Statistics } & \multicolumn{3}{|c|}{ Change Item Statistics } \\
\hline & $M$ & SD & $\begin{array}{l}\text { Item-Total } \\
\text { Correlation }\end{array}$ & $M$ & SD & $\begin{array}{l}\text { Item-Total } \\
\text { Correlation }\end{array}$ \\
\hline $\begin{array}{l}\text { 1. I feel appreciated by other } \\
\text { kids my age }\end{array}$ & 5.13 & 1.06 & 0.52 & 4.62 & 1.16 & 0.52 \\
\hline $\begin{array}{l}\text { 2. There are people in my life I } \\
\text { consider close friends }\end{array}$ & 5.73 & 0.75 & 0.67 & 5.05 & 1.04 & 0.54 \\
\hline $\begin{array}{l}\text { 3. I feel my relationships with } \\
\text { other kids my age will last }\end{array}$ & 5.33 & 0.83 & 0.62 & 4.79 & 1.08 & 0.54 \\
\hline 4. People I meet like me & 5.23 & 0.96 & 0.56 & 4.77 & 1.07 & 0.59 \\
\hline $\begin{array}{l}\text { 5. There are kids my age who } \\
\text { are important to me }\end{array}$ & 5.58 & 0.76 & 0.64 & 4.94 & 1.04 & 0.63 \\
\hline $\begin{array}{l}\text { 6. I feel the relationships with } \\
\text { my friends are stable }\end{array}$ & 5.50 & 0.74 & 0.63 & 4.78 & 1.13 & 0.72 \\
\hline 7. I feel accepted by my peers & 5.46 & 0.81 & 0.58 & 4.89 & 0.98 & 0.71 \\
\hline 8. I value my friends & 5.75 & 0.63 & 0.59 & 5.05 & 1.10 & 0.75 \\
\hline $\begin{array}{l}\text { 9. My friends are always there } \\
\text { for me }\end{array}$ & 5.29 & 0.89 & 0.56 & 4.66 & 1.11 & 0.73 \\
\hline 10. My friends care about me & 5.35 & 0.88 & 0.78 & 4.77 & 1.00 & 0.68 \\
\hline 11. I care for other kids my age & 5.56 & 0.76 & 0.64 & 5.03 & 1.07 & 0.69 \\
\hline $\begin{array}{l}\text { 12. I feel secure in the } \\
\text { relationships with my peers }\end{array}$ & 5.41 & 0.83 & 0.79 & 4.84 & 1.11 & 0.69 \\
\hline
\end{tabular}

The goal of this present study was to develop a scale of relatedness that was theoretically grounded, simple for staff to administer, and could be included in the Youth Outcomes Battery. The scale needed to be shortened to meet this aim. To shorten the scale, two items were removed from each domain based on the item's content relevance and the aforementioned statistical characteristics. Within each of the domains, the following items were kept: Question numbers 5 and 11 make up the cared for by others domain, question numbers 3 and 12 make up the duration domain, and question numbers 4 and 10 make up the caring for others domain. The final version of the instrument (see Table 2) consists of 6 items with two items per domain. The shortened scale also demonstrates appropriate levels of internal consistency with an alpha coefficient of .80 for the current status measure and .83 for the change measure. 
Table 2

Final Version of the Youth Relatedness Scale: Current Status Items Only

\begin{tabular}{|l|l|}
\hline $\begin{array}{l}\text { Question Number and } \\
\text { Content Domain }\end{array}$ & Scale Item \\
\hline Q1-Durability & I feel my relationships with other kids my age will last \\
\hline Q2-Cared for by others & Peers I meet like me \\
\hline Q3-Caring for others & There are kids my age who are important to me \\
\hline Q4-Cared for by others & Kids my age care about me \\
\hline Q5-Caring for others & I care for other kids my age \\
\hline Q6-Durability & I feel secure in relationships with my peers \\
\hline
\end{tabular}

Criterion-related evidence of validity is summarized in Table 3. In this study, the relatedness subscale of the Basic Psychological Needs Scale by La Guardia and colleagues (2000) was used as the criterion measure. The Basic Psychological Needs Scale is grounded in self-determination theory and consists of three subscales (one for each of the humans needs for autonomy, competence, and relatedness). The relatedness subscale has eight items utilizing a 7-point scale anchored at "Not True at All" and "Very True." The relatedness subscale of the Basic Psychological Needs Scale was hypothesized by the researchers to be significantly correlated with the current status measure of the Youth Relatedness Scale as both questionnaires were grounded in self-determination theory. Age was hypothesized to be unrelated to all measures. As can be seen in Table 3, the correlation between the two scales was significant $(r=.476$, $p<.01$ ). A correlation coefficient of this size suggests that while both scales are related, they are not identical and therefore show evidence of both criterion and discriminant validity. Neither of the scales were correlated with age as hypothesized.

Table 3

Correlations for Cross-structure analysis (CriterionValidity)

\begin{tabular}{|l|l|l|l|}
\hline & CRS & $\begin{array}{l}\text { CRS } \\
\text { Change }\end{array}$ & $\begin{array}{l}\text { Basic Psych. } \\
\text { Needs Scale }\end{array}$ \\
\hline CRS & 1 & & \\
\hline CRS Change & $.432^{* *}$ & 1 & \\
\hline $\begin{array}{l}\text { Basic Psych. } \\
\text { Needs Scale }\end{array}$ & $.476^{* *}$ & $.332^{* *}$ & 1 \\
\hline Age & .105 & -.100 & .120 \\
\hline
\end{tabular}

**.Correlations significant $\mathrm{p}<.01$ 


\section{Discussion}

The purpose of this study was to develop a reliable measure of relatedness that utilizes language appropriate for youth, was simple for staff to administer in an applied setting, and was consistent with the YOB. The Youth Relatedness Scale is an easy-to-use measure that exhibited good evidence of internal consistency reliability and both criterion and discriminant validity for this population of youth camp participants. The simplicity of the scale and its emphasis on durability, caring, and mutuality makes this measure stand apart from other evaluation tools that assess relatedness, and as such may have several important implications in terms of practice and future research.

\section{Implications and Limitations}

The development and use of the Youth Relatedness Scale has several important implications for practice. The Youth Relatedness Scale presented in this article was designed and tested for use with youth in a summer camp context and should be useful to those interested in measuring relatedness for youth. Measuring a sense of relatedness with a scale that is theoretically grounded, appropriate for applied settings, and empirically supported will provide a mechanism to assist youth professionals in answering the following question: Do your program experiences help youth feel a greater sense of relatedness? Program level characteristics such as the social environment, staff-participant relationships, and challenging activities have a significant impact on youth perceptions of relatedness (Rhodes, 2004). These program-level characteristics and their relationships to participant relatedness could be assessed utilizing the Youth Relatedness Scale. Through evaluating intentionally designed programs, professionals will be able to advance best practices and develop effective strategies for instilling a sense of relatedness among youth.

The Youth Relatedness Scale includes both a status and change measure, both of which program administrators can use to determine program effectiveness. The status measure of the scale can be used in the traditional pretest/posttest format. For persons with cognitive disabilities and for younger children, this format may be the most effective. This format may also be preferable to investigators who wish to understand the relationships between program and participant-level variables and the outcome variable relatedness. The retrospective change format may be an efficient method for program staff to evaluate the effect of program participation on youth perceptions of relatedness. While logistically easier, the retrospective change format may not be appropriate in all settings (see Lam \& Bango, 2003; Sibthorp et al., 2007).

This study has limitations. First, this study employed a convenience sample of 175 campers from three ACA accredited summer camps, and therefore is not representative of all youth. Second, the sample included participants covering a wide range of ages (10-16). While the items were designed to meet the needs of youth, the participants in this study represent a wide age range. Age was not correlated with the Youth Relatedness Scale, however, this study did not assess issues pertaining to the developmental characteristics (e.g., identity formation, social-cognitive functioning, and moral reasoning) of the sample. Third, the evidence of validity was limited to one self-report instrument. Because of this, additional validity work assessing construct and criterion-related validity is desirable as the scale becomes more widely used. 
Future research should be conducted to assess the validity and utility of this scale. The Youth Relatedness Scale needs to be tested in a variety of settings with different youth populations to further assess its utility. Many youth serving programs are concerned with instilling a sense of relatedness among its participants. While this study developed and tested the scale utilizing a camp setting, future research may want to investigate its use in other youth serving programs such as after-school programs and community recreation programs. In addition to program type, evidence should also be collected that illuminates any differences in the internal structure due to participant characteristics such as identity formation, disability, sex, and ethnicity. More specifically, the retrospective change format should be tested using youth with disabilities, especially youth with cognitive disabilities, to assess the extent to which this evaluation method yields valid and appropriate inferences about participant growth.

Continued efforts to test the questionnaire and collect evidence of both reliability and validity are necessary to understand the effectiveness of this scale in measuring the relatedness construct. Research suggests that a sense of relatedness may be associated with youth's participation and engagement in program activities, as well as overall enjoyment and sense of community (Anderson-Butcher \& Conroy, 2002). These relationships could be tested using this scale, and by extension, provide evidence of predictive validity.

\section{Conclusion}

Professionals in youth serving fields are experiencing an increased pressure to document the developmental outcomes that result from participation in these programs. Program administrators need access to measures that are easy to administer and interpret so they can effectively document participant growth. One outcome of interest to many youth serving programs is relatedness. The instrument developed in this study was a positive step towards providing a theoretically grounded, simple, and versatile measure that captures youth perceptions of relatedness and that program administrators can employ to intentionally design and evaluate their programs. Fundamental to program improvement is the ability to understand what the underlying processes are within the program that facilitate participant growth. Future research should focus on utilizing measures like the Youth Relatedness Scale to illuminate the mechanistic processes that occur during summer camp and other youth programs, so that researchers and programmers can better understand how and why these programs achieve positive outcomes for youth.

\section{References}

American Camp Association. (2011). Camp Youth Outcomes Battery: Measuring developmental outcomes in youth programs ( $\left.2^{\text {nd }} \mathrm{ed}\right)$. Author.

American Camp Association. (2005). Directions: Youth development outcomes of the camp experience. Author.

Anderman, E. M., \& Maehr, M. L. (1994). Motivation and schooling in the middle grades. Review of Educational Research, 64(2), 287-309. 
Anderman, L.H. (1999). Classroom goal orientation, school belonging and social goals as predictors of students' positive and negative affect following the transition to middle school. Journal of Research and Development in Education, 32(1), 89-103.

Anderson-Butcher, D. (2000). The relationships among engagement in youth development programs, risk and protective factors, and problem behaviors: An exploratory study. doctoral dissertation. University of Utah.

Anderson-Butcher, D., \& Conroy, D.E. (2002). Factorial and criterion validity of scores of a measure of belonging in youth development programs. Educational \& Psychological Measurement, 62(5), 857-877.

Baumeister, R.F., \& Leary, M.R. (1995). The need to belong: Desire for interpersonal attachments as a fundamental human need. Psychological Bulletin, 1173), 497-529.

Caldwell, M.A., \& Peplau, L.A. (1982). Sex differences in same sex friendship. Sex Roles, 8(7), 721-732.

Catalano R.F., Haggerty K.P., Oesterle S., Fleming C.B., \& Hawkins, J.D. (2004). The importance of bonding to school for healthy development: Findings from the Social Development Research Group. Journal of School Health, 74(7), p. 252-261.

Deci, E.L., \& Ryan., R.M. (1985). Intrinsic motivation and self-determination in human behavior. New York: Plenum Press.

Deci, E.L., \& Ryan, R.M. (2000). The 'what' and 'why' of goal pursuits: Human needs and the self-determination of behavior. Psychological Inquiry, 11(4), 227-268.

DeVellis, R.F. (2003). Scale development: Theory and applications. Thousand Oaks, CA: Sage.

Eccles, J., \& Gootman, J.A. (2002). Community programs promote youth development. Washington, DC: National Academy Press.

Ellis, G., \& Sibthorp, J. (2006). Final Report: Measurement of Camp Outcomes Project. Martinsville, IN: American Camp Association.

Fajans, J. (2006). Individuality and sociality autonomy and relatedness: Emotions and the tension between individuality and sociality. Critique of Anthropology, 26(1), 103-119.

Fullerton, A.B., Brannan, S., \& Arick, J. (2000). Qualitative outcomes for youth who participate in inclusive programs: A multi-case analysis across 14 camps and outdoor schools. Coalitions for Education in the Outdoors Research Symposium Proceedings. January, Bradford Woods, IN.

Furrer, C.J., \& Skinner, E.A. (2003). Sense of relatedness as a factor in children's academic engagement and performance. Journal of Educational Psychology, 95(1), 148-162.

Gest, S.D., Welsh, J.A., \& Domitrovich, C.E. (2005). Behavioral predictors of changes in social relatedness and liking school in elementary school. Journal of School Psychology, 43(4), 281301. 
Goodenow, C. (1993). The psychological sense of school membership among adolescents: Scale development and educational correlates. Psychology in the Schools, 30(1), 79-90.

Grossman, J.B., \& Bulle, M.J. (2006). Review of what youth programs do to increase the connections of youth and adults. Journal of Adolescent Health, 39(6), 788-799.

Hagerty, B.M.K., Lynch-Sauer, J., Patusky, K.L., \& Bouwsema, M. (1993). An emerging theory of human relatedness. Journal of Nursing Scholarship, 25(4), 291-296.

Hagerty, B.M.K., \& Patusky, K. (1995). Developing a measure of sense of belonging. Nursing Research, 44(1), 9-13.

Henderson, K.A., Bialeschki, D.M., Scanlin, M.M.,Thurber, C. Whitaker, L.S., \& Marsh, P.E. (2002). Components of camp experiences for positive youth development. Journal of Youth Development, 1(3), 1-10.

Ilardi, B.C., Leone, D., Kasser, R., \& Ryan, R.M. (1993). Employee and supervisor ratings of motivation: Main effects and discrepancies associated with job satisfaction and adjustment in a factory setting. Journal of Applied Social Psychology, 23(21), 1789-1805.

La Guardia, J.G., Ryan, R.M., Couchman, C.E., \& Deci, E.L. (2000). Within-person variation in security of attachment: A self-determination theory perspective on attachment, need fulfillment, and well-being. Journal of Personality and Social Psychology, 79(3), 367-384.

Lam, T., \& Bengo, P. (2003) A comparison of three retrospective self-reporting methods of measuring change in instructional practice. American Journal of Evaluation, 24(1), 65-80.

MacDonald, G.B., \& Valdivieso, R. (2000). Measuring deficits and assets: How we track youth development now, and how we should track it. In N. Jaffe (Ed.), Youth development: Issues, challenges, directions (pp.149-184). Philadelphia, PA: Public/Private Venture.

Myers, D.G. (1992). The pursuit of happiness: Who is happy-and why. New York: William Morrow.

Omizo, M.A., Omizo, S.A., \& Honda, M.R. (1997). A phenomenological study with youth gang members: Results and implications for school counselors. Professional School Counseling, 1(1), $39-42$.

Osterman, K.F. (2000). Students' need for belonging in the school community. Review of Educational Research, 70(3), 323-368.

Ostrom, T.M., Li, F., Carpenter, S.L., \& Sedikides, C. (1993). Differential processing of in-group and out-group information. Journal of Personality \& Social Psychology, 64(1), 21-34.

Rhodes, J.E. (2004). The critical ingredient: Caring youth-staff relationships in after-school settings. New Directions for Youth Development, 2004(101), 145-161. 
Roark, M. (2008). Relationships among selected features of camps, the nature of interactions between and characteristics of camp personnel and campers, and campers' acquisition of developmental outcomes relevant to the self-determination theory. doctoral dissertation. University of Utah.

Ryan, R.M., \& Deci, E.L. (2000). Within-person variation in security of attachment: A selfdetermination theory perspective on attachment, need fulfillment, and well-being. Journal of Personality and Social Psychology, 79(3), 367-384.

Ryan, R.M., \& Deci, E.L. (2004). Overview of self-determination theory: an organismic dialectical perspective. In E. L. Deci \& R. M. Ryan (Eds.), Handbook of self-determination theory (pp. 3-35). Rochester, NY: University of Rochester Press.

Samulesson, M.A.K. (1997). Social networks of children in single-parent families: Differences according to sex, age, socioeconomic status and housing-type and their Associations with behavioral disturbances. Social Networks, 19(2), 113-127.

Schaefer-McDaniel, M.J. (2004). Conceptualiziing social capital among young people: Towards a new theory. Children, Youth and Environments, 14(1), 140-150.

Shaver. P., \& Buhrmester, D. (1983). Loneliness, sex-role orientation, and group life: A social needs perspective. In P. Paulus (Ed.), Basic group processes (pp. 259-288). New York: Springer-Verlag.

Sibthorp, J., Paisley, K., Gookin, J., \& Ward, P. (2007). Addressing response-shift bias: Retrospective pretests in recreation research and evaluation. Journal of Leisure Research, 39(2), 295-315.

Simone, P., \& Roberts, M. (2008). Addressing loneliness in later life. Aging \& Mental Health, 12(3), 302-309.

Solomon, D., Battistich, V., Watson, M., Schaps, E., \& Lewis, C. (2000). A six-district study of educational change: Direct and mediated effects of the child development project. Social Psychology of Education, 4(1), 3-51.

Tabachnick, B.G., \& Fidell, L.S. (2001). Using multivariate statistics. California State University, Northridge: Harper Collins.

Thurber, C.A., Scanlin, M.M., Scheuler, L., \& Henderson, K.A. (2006). Youth development outcomes of the camp experience: Evidence for multidimensional growth. Journal of Youth \& Adolescence, 36(3), 241-254.

Vaquera, E., \& Kao, G. (2008). Do you like me as much as I like you? Friendship reciprocity and its effects on school outcomes among adolescents. Journal of Adolescent Health, 371), 55-72.

Vigil, J.D. (2004). Gangs and group membership: implications for schooling. In Gibson, M.A., Gándara, P., \& Koyama, J.P. (Eds.), School connections: U.S. Mexican youth, peers, and school achievement (pp. 87-106). New York: Teachers College Press. 
Wentzel, K.B., \& Caldwell, K. (1997). Friendships, peer acceptance, and group membership: Relations to academic achievement in middle school. Child Development, 68(6), 1198-1209.

Wentzel, K.B. (1998). Academic and social motivational influences on students' academic performance. Educational Psychology Review, 10(2), 155-176.

Whitlock, J.L. (2006). Youth perceptions of life at school: Contextual correlates of school connectedness in adolescence. Applied Developmental Science, 10(1), 13-29.

(C) Copyright of Journal of Youth Development Bridging Research and Practice. Content may not be copied or emailed to multiple sites or posted to a listserv without copyright holder's express written permission. However, users may print, download or email articles for individual use. 